\title{
Organic Reaction in Water. Part 31: Diastereoselectivity in Michael Additions of Thiophenol to Nitro Olefins in Aqueous Media
}

\author{
Flavia M. da Silva and Joel Jones Jr*. \\ Departamento de Química Orgânica, Instituto de Química, Universidade Federal \\ do Rio de Janeiro, C. P. 68545, 21945-970, Rio de Janeiro - RJ, Brazil
}

\begin{abstract}
Tiofenóis reagem com nitro olefinas em meio aquoso dando os correspondentes nitro-sulfetos em 58 - $95 \%$ de rendimento. Este processo leva à formação, predominante, de produtos anti. Para o caso da nitro olefina cíclica 1-nitro-ciclo-hexeno é observada unicamente a formação de cis-1nitro-2-(tio-fenil)-ciclo-hexano. Esta metodologia é interessante porque utiliza-se água como solvente levando à minimização do custo, diminuindo os problemas de toxidez e poluição ambiental

Thiophenol reacts with nitro olefins in aqueous media to give the corresponding nitro-sulfides in 58-95\% yield. This procedure results in selective formation of the anti products. In the case of the cyclic nitro olefin 1-nitro-cyclohexene the only product observed was the cis-1-nitro-2(phenylthio)cyclohexane. This methodology is of interest due to the use of water as solvent, thus minimizing the cost, the operational hazards and environmental pollution.
\end{abstract}

Keywords: Michael additions in water, nitro olefins, thio compounds

\section{Introduction}

Two of the most characteristic features of thiols are the relatively high acidity and the facility with which they undergo nucleophilic reactions ${ }^{2}$. Thiols are, therefore, good substrates for Michael addition reactions, which are conventionally promoted in the presence of catalytic amounts of sodium methoxide or triethylamine ${ }^{3}$. Procedures using Triton $\mathrm{B}^{4}$ and quaternary ammonium fluoride ${ }^{5}$ as catalysts have been previously published.

Modern methods mediated by resins and heterogeneous catalysts have also been employed. The Dowex MAS-1 impregnated with fluoride ${ }^{6}$ and $\mathrm{BER}^{7}$ give good results. Ranu and $\mathrm{Bhar}^{8}$ developed an interesting procedure for Michael addition on the surface of alumina. Transition metal complexes have many applications as catalysts for this kind of reaction, particularly for the asymmetric variant ${ }^{9}$.

Recently, we showed that Michael addition of dicarbonyl compounds, nitroalkanes and thiols to the 2-cyclohexen-1-one can be accomplished in water without phase transfer agents. We also observed that the reaction is extremely sensitive to the $\mathrm{pH}$ of the reaction media, and depending on the nucleophile, the optimized $\mathrm{pH}$ is different ${ }^{1}$.

\footnotetext{
*e-mail: jjones@ufrj.br
}

This work has importance for the study of organic reactions in aqueous media. This field of study has grown steadily since Breslow demonstrated, in 1980, the use of the hydrophobic effect to promote Diels-Alder reactions ${ }^{10}$. Examples of reactions performed in aqueous media in the sub- ${ }^{11}$ and super-heated ${ }^{12}$ states can be found in the literature.

Apart from the physical chemistry aspects which stimulate academic interest and can be useful in organic synthesis, the use of water as a reaction medium to substitute organic solvents is important for human and economic reasons as it minimizes environmental impact, reduces the cost and presents smaller operational hazards.

In this work, we have studied the Michael addition of thiophenol to nitro olefins in aqueous media to form nitrosulfides (Scheme 1). An anti diastereoselectivity was observed that is quite different from that encountered using the traditional method with triethylamine as base and acetronitrile as solvent (Scheme 2, method A), whilst the diastereoselectivity is similar to that observed by Kamimura where the addition of thiolates is followed by protonation with acetic acid at $-78^{\circ} \mathrm{C}$ in THF as solvent (Scheme 2, method B).

\section{Results and Discussion}

The reaction of (E)-1-methyl-1-nitro-styrene (1a) with thiophenol was studied under three different conditions, with 
<smiles>[R]C=C(C)[N+](=O)[O-]</smiles>
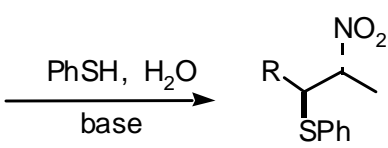

2-anti

$1 \mathrm{a}-\mathrm{c}$

$5 \mathrm{mmol}$ of thiophenol in $10 \mathrm{~mL}$ of $0.5 \mathrm{~mol} \mathrm{~L}^{-1}$ aq. base solution $\left(\mathrm{NaOH}, \mathrm{Na}_{2} \mathrm{CO}_{3}\right.$ or $\left.\mathrm{NaHCO}_{3}\right)$

\begin{tabular}{clccl}
\hline $\mathrm{R}$ & \multicolumn{1}{c}{ Base $(\mathrm{pH})$} & Time (min) & yield (\%) & \multicolumn{1}{c}{ anti/syn } \\
\hline $\mathrm{Ph} \mathrm{(1a)})$ & $\mathrm{NaHCO}_{3}(7-10)$ & & 95 & $73 / 27(\mathbf{2 a})^{13}$ \\
& $\mathrm{Na}_{2} \mathrm{CO}_{3}(10)$ & 30 & 85 & $69 / 31(\mathbf{2 a})$ \\
& $\mathrm{NaOH}(14)$ & & - & $71 / 29(\mathbf{2 a})$ \\
$\mathrm{Et}(\mathbf{1 b})$ & $\mathrm{NaHCO}_{3}(7-10)$ & 40 & 70 & $80 / 20(\mathbf{2 b})^{14}$ \\
$\operatorname{iPr}(\mathbf{1 c})$ & $\mathrm{NaHCO}_{3}(7-10)$ & 120 & 58 & $38 / 62(\mathbf{2 c})^{15}$ \\
\hline
\end{tabular}

Scheme 1. Reaction of nitro olefin with thiophenol in water.
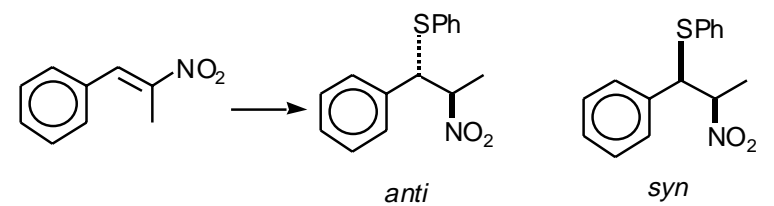

method A: $\mathrm{PhSH}, \mathrm{Et}_{3} \mathrm{~N}, \mathrm{CH}_{3} \mathrm{CN}$, t.a, 1h; antisyn: $34: 66$ method B: (i) PhSLi, THF, t.a.; (ii) $-78^{\circ} \mathrm{C}, \mathrm{AcOH}, 2 \mathrm{~h}$, anti:syn: 75:25

Scheme 2. Michael addition of thiophenol to (2-nitroprop-1enyl)benzene ${ }^{3}$.

the main variant being the $\mathrm{pH}$ of the reaction media. The reaction was catalysed with $\mathrm{NaOH}(\mathrm{pH} 14), \mathrm{Na}_{2} \mathrm{CO}_{3}(\mathrm{pH}$ 10) or $\mathrm{NaHCO}_{3}(\mathrm{pH} 7-10)^{16}$.

Using the above conditions, diastereoselectivity was observed and a 70:30 (anti:syn) mixture of nitro-olefins (2a) was obtained ${ }^{14}$. However, at $\mathrm{pH} 14$ the substrate was not totally consumed.

When the mixture of isomers $2 \mathbf{a}$ (73:27, anti: syn) was treated with an aqueous solution of $\mathrm{NaOH}(\mathrm{pH} 14)$, the formation of nitro olefin 1a and thiophenol was observed, after $30 \mathrm{~min}$. Thus, we conclude that at $\mathrm{pH} 14$ the product can suffer a retro-Michael reaction.

Having found that the reaction proceeds in good yields and under mild conditions in aqueous $\mathrm{NaHCO}_{3}$, we decided to further investigate the use of this media.

The analogous reaction with (E)-2-nitro-2-pentene (1b) results in the addition products in an anti:syn ratio of 80:20.

On the other hand, when a bulky substituent such as isopropyl in $\mathbf{1} \mathbf{c}$ is present, the stereoselectivity is markedly decreased, leading to a 38:62 mixture of the anti:syn products, as also verified by Kamimura ${ }^{3}$. It was further noted that the reaction was slowed down and that the substrate was not totally consumed.

We also verified, that this method was useful for the stereoselective preparation of cis-1-nitro-(phenylthio) cyclohexane (2d) ${ }^{17}$ by the reaction of 1-nitro-cyclohexene (1d) with thiophenol (Scheme 3).

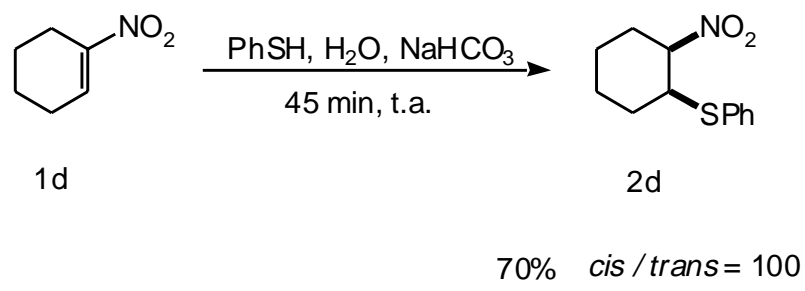

Scheme 3. Reaction of 1-nitrocyclohexene with thiophenol in water.

Kamimura and coworkers ${ }^{3}$ observed anti selectivity for the addition of several metal thiolates to nitro-olefins in $\mathrm{THF}$, followed by acetic acid treatment at $-78^{\circ} \mathrm{C}$ (Scheme 2 , method B). They attributed this selectivity to the protonation stage of the nitronate anion and theorized that this may occur in the perpendicular conformation shown in Figure 1. Thus, the $\mathrm{R}^{3} \mathrm{~S}$ group covers one face of the nitronate group explaining the diastereoselectivity. In order to ascertain the preferred structure of the intermediates, Kamimura and coworkers ${ }^{3}$ also carried out ab initio molecular orbital (MO) calculations which provided support for the proposed conformation.

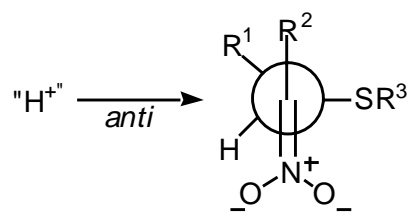

Figure 1. Most stable conformer of nitronate.

The proposed intermediate (Figure 1) also explains the observed selectivity in water, but it is important to point out that in water the process occurs at room temperature $\left(25-30^{\circ} \mathrm{C}\right)$.

\section{Conclusions}

Thus, we concluded that thiophenol reacts with nitroolefins 1a and $\mathbf{1 b}$ in aqueous media leading to the corresponding $\beta$-nitro-sulfides in good yields and with anti selectivity. However, when 3-methyl-2-nitro-3-pentene (1c) was used the selectivity was inverted and markedly decreased. The anti selectivity is not $\mathrm{pH}$ dependent but the yield of the reaction decreases at high $\mathrm{pH}$ values because the products can suffer a retro-Michael reaction. This methodology is of interest due to the use of water as the solvent, thus minimizing the cost as well as operational hazards and environmental pollution.

\section{Acknowledgments}

We are grateful to Conselho Nacional de Desenvolvimento Científico e Tecnológico for a fellowship to F.M.S., 
Fundação José Bonifácio for additional financial support of this work and A. M. Sanseverino for the good ideas in the synthesis of the necessary nitro olefins for this study.

\section{References}

1. da Silva, F. M.; Gomes, A. K.; Jones, J. Jr. Can. J. Chem. 1999, 77, 624.

2. Whitham, G. H. In Organosulfur Chemistry, Oxford Univerty Press Inc.New York, 1995, 33, p 4.

3. Kamimura, A.; Sasatani, H.; Hashimoto, T.; Kawai, T.; Hori. K.; Ono, N. J. Org. Chem. 1990, 55, 2437.

4. Hurd, C. D.; Gershbein, L. L. J. Am. Chem. Soc. 1947, 69, 2328.

5. Kuwajima, I.; Murofushi, T.; Nakamura, E. Synthesis 1976, 602.

6. Miller, J. M.; So, K-H.; Clark, J.H. J. Chem. Soc. Chem. Comm. 1978, 466.

7. Lee, D. W.; Choi, J.; Yoon, N. M. Synth Commun. 1996, 26, 2189.

8. Ranu, B. C.; Bhar, S. Tetrahedron 1992, 48, 1327.

9. (a) Ahuja, R. R.; Natu, A. A.; Gogte, V. N. Tetrahedron Lett. 1980, 21, 4743. (b) Manickam, G.; Sundararajan, G. Tetrahedron: Asymmetry 1997, 8, 2271. (c) Emori, E.; Arai, T.; Sasai, H.; Shibasaki, M. J. Am. Chem. Soc. 1998, 120, 4043.

10. Rideout D. C.; Breslow R. J. Am. Chem. Soc. 1980, 102, 7816.

11. (a) Lubineau, A.; Augé, J.; Queneau, Y. Synthesis 1994, 741; (b).King, J. F.; Rathore, R.; Lam, J. Y. L.; Guo, Z. R.; Klassen, D. F. J. Am. Chem. Soc.1992, 114, 3028; (c).Breslow, R., Acc. Chem. Res 1991, 24, 159; (d) Li C. -J Tetrahedron 1996, 52, 5646; (e) Li, C.-J.; Chan, T.-H. In Organic Reaction in Aqueous Media; New York; John Wiley \& Sons, Inc. 1997, p 198; (f) Grieco, P. A. In Organic Synthesis in Water; London; Blackie Academic \& Professional, 1998, p 310.

12. (a) Kuhlmann, B.; Arnett, E. M.; Siskin, M. J. Org. Chem 1994, 59, 3098; (b) Katritzky A. R.; Allin, S. M. Acc. Chem. Res. 1996, 29, 399.

13. 2-Nitro-1-phenyl-1-(phenylthio)propane (2a): anti/syn $=73 / 27 ;(\text { anti-2a })^{3}-{ }^{1} \mathrm{H} \mathrm{NMR}\left(300 \mathrm{MHz}, \mathrm{CDCl}_{3}\right) \delta$ $1.81(\mathrm{~d}, J 6.6 \mathrm{~Hz}, 3 \mathrm{H}), 4.57$ (d, J 9.4Hz, 1H), 4.90-4.99 (m, 1H), 7.20-7.30 (m, 10H); (syn-2a) ${ }^{3}$ - ${ }^{1} \mathrm{H} \mathrm{NMR}(300$ $\left.\mathrm{MHz}, \mathrm{CDCl}_{3}\right) \delta 1.40(\mathrm{~d}, J 6.7 \mathrm{~Hz}, 3 \mathrm{H}), 4.55(\mathrm{~d}, J 9.4 \mathrm{~Hz}$,
1H) 4.90-4.99 (m, 1H), 7.20-7.30 (m, 10H); (anti/syn2a) $-{ }^{13} \mathrm{C} \mathrm{NMR}\left(75 \mathrm{MHz}, \mathrm{CDCl}_{3}\right) \delta 17.7,18.2,56.9$, 57.4, 86.5, 87.0, 128.1, 128.3, 128.4, 128.5, 128.6, 128.7, 128.8, 129.2, 133.9, 134.2, 136.6, 137.6.

14. 2-Nitro-3-(phenylthio)pentane $(2 \boldsymbol{b})$ : anti/syn $=80 / 20$; $(\text { anti-2b) })^{3}-{ }^{1} \mathrm{H}$ NMR $\left(300 \mathrm{MHz}, \mathrm{CDCl}_{3}\right) \delta 1.15(\mathrm{t}, J$ $7.3 \mathrm{~Hz}, 3 \mathrm{H}), 1.66(\mathrm{~d}, J 6.7 \mathrm{~Hz}, 3 \mathrm{H}) 1.45-1.76(\mathrm{~m}, 2 \mathrm{H})$, 3.41 (ddd, J 4.6, 7.6, 9.2Hz, 1H), 4.60 (quint, $J 6.7 \mathrm{~Hz}$, 1H), 7.25-7.45 (m, 5H); (syn-2b) $)^{3}-{ }^{1} \mathrm{H}$ NMR (300 $\left.\mathrm{MHz}, \mathrm{CDCl}_{3}\right) \delta 1.15(\mathrm{t}, J 7.3 \mathrm{~Hz}, 3 \mathrm{H}), 1.60(\mathrm{~d}, J 5.1 \mathrm{~Hz}$, $3 \mathrm{H}), 1.45-1.76(\mathrm{~m}, 2 \mathrm{H}), 3.58$ (ddd, J 3.4, 5.5, $10.1 \mathrm{~Hz}, 1 \mathrm{H}), 4.60$ (quint, $J 6.7 \mathrm{~Hz}, 1 \mathrm{H}), 7.20-7.45$ (m, $5 \mathrm{H}) ;\left(\right.$ anti/syn-2b) $-{ }^{13} \mathrm{C} \mathrm{NMR}\left(75 \mathrm{MHz}, \mathrm{CDCl}_{3}\right) \delta$ 11.6, 11.8, 14.0, 16.6, 22.2, 25.3, 55.2, 85.1, 86.2, 128.1, 129.2, 132.4, 133.1, 133.4.

15. 2-nitro-3-(phenylthio)-4-methylpentane (2c): anti/syn $=38 / 62 ;(\text { anti-2c })^{3}-{ }^{1} \mathrm{H}$ NMR $\left(200 \mathrm{MHz}, \mathrm{CDCl}_{3}\right) \delta$ $0.95(\mathrm{~d}, J 6.7 \mathrm{~Hz}, 3 \mathrm{H}), 1.12$ (d, $J 6.7 \mathrm{~Hz}, 3 \mathrm{H}), 1.63(\mathrm{~d}, J$ $6.7 \mathrm{~Hz}, 3 \mathrm{H}), 2.22(\mathrm{~m}, 1 \mathrm{H}), 3.48(\mathrm{dd}, J 4.4,8.9 \mathrm{~Hz}, 1 \mathrm{H})$, $4.70(\mathrm{~m}, 1 \mathrm{H}), 7.25-7.45(\mathrm{~m}, 5 \mathrm{H}) ;(\text { syn-2c })^{3}-{ }^{1} \mathrm{H}$ NMR $\left(200 \mathrm{MHz}, \mathrm{CDCl}_{3}\right) \delta 1.04(\mathrm{~d}, J 6.7 \mathrm{~Hz}, 3 \mathrm{H}), 1.17(\mathrm{~d}, J$ $6.7 \mathrm{~Hz}, 3 \mathrm{H}), 1.63$ (d, J 6.7 Hz,3H), 1.90 (m, 1H), 3.48 $(\mathrm{dd}, J 4.4,8.9 \mathrm{~Hz}, 1 \mathrm{H}), 4.70(\mathrm{~m}, 1 \mathrm{H}), 7.25-7.45(\mathrm{~m}$, $5 \mathrm{H})$; (anti/syn-2c) $-{ }^{13} \mathrm{C} \mathrm{NMR}\left(75 \mathrm{MHz}, \mathrm{CDCl}_{3}\right) \delta 17.1$, 17.5, 17.7, 21.3, 21.7, 29.1, 30.3, 60.0, 61.2, 86.1, 86.7, 127.2, 127.4, 129.1, 129.2, 131.4, 131.8, 135.1, 135.9.

16. Typical procedure. Thiophenol $(5 \mathrm{mmol})$ was added to $0.5 \mathrm{~mol} \mathrm{~L}^{-1}$ aqueous base $(10 \mathrm{~mL})$. Soon after, nitro olefin $(5 \mathrm{mmol})$ was added. The reaction medium was then stirred vigorously during the time indicated in Scheme 1. After this time, the phases were separated and the aqueous phase was extracted with chloroform. The organic phase and the organic extract were mixed, dried (anhyd. $\mathrm{Na}_{2} \mathrm{SO}_{4}$ ) and the solvent was evaporated under reduced pressure. Pure nitro sulfides were obtained, except the nitro-sulfide 2c which was separated from the reagents by preparative plate chromatograph. Diastereomeric ratios were determined by HRGC. All spectral data are in agreement with Kamimura ${ }^{3}$.

17. cis-1-Nitro-2-(phenylthio) cyclohexane $(2 d):{ }^{1} \mathrm{H} \mathrm{NMR}$ $\left(200 \mathrm{MHz}, \mathrm{CDCl}_{3}\right)^{3} \delta 1.22-2.24(\mathrm{~m}, 8 \mathrm{H}), 3.84(\mathrm{~m}$, $1 \mathrm{H}), 4.58$ (dt, $J 9.8,4.3 \mathrm{~Hz}, 1 \mathrm{H}), 7.25-7.50(\mathrm{~m}, 5 \mathrm{H})$; ${ }^{13} \mathrm{C} \mathrm{NMR}\left(75 \mathrm{MHz}, \mathrm{CDCl}_{3}\right) \delta 21.4,22.8,26.6,30.9$, 51.0, 85.7, 127.3, 127.6, 128.1, 129.2, 133.2, 134.3.

Received: September 22, 2000 Published on the web: April 11, 2001 